\title{
UMA ANÁLISE DAS CONCEPCÕ̃ES QUE PERMEIAM A FORMAÇÃO PROFISSIONAL DO PRONATEC
}

\author{
MARIA CLARISSE VIEIRA \\ RENATO HILÁRIO DOS REIS \\ JULIETA BORGES LEMES SOBRAL
}

\section{RESUMO}

Este artigo tem como objetivo compreender e discutir algumas das principais concepções de educação e trabalho que permeiam a formação do trabalhador brasileiro, com base na análise da criação do Programa Nacional de Acesso ao Ensino Técnico e Emprego, o Pronatec, instituído em 2011. O texto apresenta um breve histórico das concepções que envolvem a formação do trabalhador presentes no final da década de 1980 e 1990, no âmbito da elaboração e aprovação da Lei n. 9.394/1996, que se estabelece até a primeira década do século XXI. Com base em análise documental e na legislação do período, dialoga com a produção acadêmica que permeia os campos da educação e trabalho e educação de jovens e adultos, analisando em que medida o Pronatec tende a fortalecer a dualidade estrutural do capitalismo ou a criar espaços emancipatórios, que possibilitem uma educação pautada na integração entre formação profissional e formação básica.

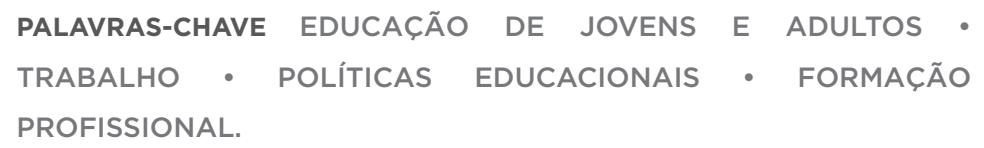




\section{UN ANÁLISIS DE LAS CONCEPCIONES QUE PERMEAN LA FORMACIÓN PROFESIONAL DE PRONATEC}

RESUMEN

Este artículo tiene el objetivo de entender y discutir algunas de las principales concepciones de educación y trabajo que permean la formación del trabajador brasileño, en base al análisis de la creación del Programa Nacional de Acesso ao Ensino Técnico e Emprego, Pronatec, que se instituyó en el 2011. El texto presenta un breve historial de las concepciones relacionadas con la formación del trabajador a fines de las décadas de 1980 y 1990, en el marco de la preparación y aprobación de la Ley n. 9.394/1996, que se establece hasta la primera década del siglo XXI. En base al análisis documental y a la legislación del periodo, dialoga con la producción académica que permea los campos de la educación y trabajo y de la educación de jóvenes y adultos, analizando en qué medida Pronatec tiende a fortalecer la dualidad estructural del capitalismo o a crear espacios de emancipación, que posibiliten una educación basada en la integración entre formación profesional y formación básica.

PALABRAS CLAVE EDUCACIÓN DE JÓVENES Y ADULTOS • TRABAJO • POLÍTICAS EDUCACIONALES・FORMACIÓN PROFESIONAL.

\section{AN ANALYSIS OF THE CONCEPTS THAT PERMEATE THE PRONATEC PROFESSIONAL TRAINING}

ABSTRACT

This article aims to understand and discuss some of the main concepts of education and work involving the training of the Brazilian worker based on the analysis of the creation of the Programa Nacional de Acesso ao Ensino Técnico e Emprego [National Program of Technical Education and Employment Access], Pronatec, established in 2011. The text presents a brief account of the ideas involved in the training of the worker at the end of the 1980s and 1990s, amid the drafting and approval of Law 9394/96 instituted by the end of the first decade of the 21st century. The article is based on documentary analysis and on the education laws of that period. It interacts with academic work in the fields of education and work, as well as the education of youth and adults. It examines the extent to which Pronatec strengthens the structural duality of capitalism, or creates emancipative spaces which allow education to be based on the integration between professional and basic training.

KEYWORDS YOUTH AND ADULT EDUCATION • WORK • EDUCATIONAL POLICIES - PROFESSIONAL TRAINING. 
1 A dotação orçamentária de oito bilhões de reais para o Pronatec refere-se aos anos de 2012 e 2013

\section{APRESENTAÇÃO DA TEMÁTICA}

O objetivo do nosso artigo é analisar o Programa Nacional de Acesso ao Ensino Técnico e Emprego (Pronatec), instituído pela Lei n. 12.513, de 26 de outubro de 2011. A decisão de estudarmos o Pronatec parte do reconhecimento da abrangência desse programa que, segundo dados divulgados pelo Instituto de Pesquisa Econômica Aplicada (Ipea), buscou atingir uma meta de oito milhões de vagas de educação profissional ao longo de quatro anos, de 2011 a 2014 (CASSIOLATO; GARCIA, 2014, p. 21), com um investimento da ordem de oito bilhões de reais (CASSIOLATO; GARCIA, 2014, p. 36). ${ }^{1}$ Diante da grande envergadura do programa, buscamos analisá-lo à luz das concepções que estão em disputa, seja no espaço da construção da política pública de formação do trabalhador brasileiro, seja na significação de cada indivíduo que vive sob a égide do modo de produção capitalista.

Na realização desse estudo, apoiamo-nos em análise documental e na legislação produzida no período, dialogando com a produção acadêmica que permeia os campos da educação e trabalho e da educação de jovens e adultos. 
Para isso, realizamos um breve resgate histórico das principais concepções que envolvem a formação do trabalhador presentes no final da década de 1980 e 1990, no âmbito da elaboração e aprovação da Lei n. 9.394, de 20 de dezembro de 1996, que estabelece as diretrizes e bases da educação nacional (conhecida como LDBEN n. 9.394/96), passando pela primeira década do século XXI até a criação do Pronatec, em 2011. Com isso, trazemos à tona a disputa entre as concepções de conformidade à lógica do capital, que compreendem o processo educativo como um meio para o aumento da produtividade e do lucro no capitalismo, e as de emancipação humana, que tendem a compreender o processo educativo como meio para um processo de libertação do homem e superação das opressões e injustiças geradas pela lógica do capital, que permeiam nossas significações do que seja o objetivo dessa formação e, consequentemente, revelam-se nas legislações e programas implementados no âmbito das políticas púbicas de educação profissional e tecnológica.

\section{DISPUTAS ENTRE CONCEPÇÕES NA FORMAÇÃO DO TRABALHADOR - BREVE RETROSPECTIVA HISTÓRICA}

Ao analisar a construção histórica das políticas públicas de educação profissional para formação dos sujeitos jovens, adultos e idosos da classe trabalhadora, percebemos, conforme descrito por Bastos e Vitorette (2011, p. 327), que existem concepções em disputas, em outras palavras, projetos de classe que estão lutando entre si pela hegemonia no espaço de construção e implementação das políticas públicas. Disputas que se situam entre o projeto que está mais alinhado com o atendimento dos interesses do capital e o projeto que visa à defesa do trabalho, da formação integral do sujeito, como centralidade do processo educativo. Com vistas a apresentar essas disputas, realizamos um breve resgate histórico, a partir do final da década de 1980, da elaboração da Lei de Diretrizes e Bases da Educação Nacional (LDBEN), até 2011, com a lei de criação do Programa Nacional de Acesso ao Ensino Técnico e Emprego. 
2 SAVIANI, Dermeval. A nova LDB: entrevista com Dermeval Saviani. Proposições, Campinas, n. 1 p. 7-13, mar. 1990
A PROPOSTA DA POLITECNIA: FORMAÇÃO PROFISSIONAL INTEGRADA, TRABALHO, CIÊNCIA, TECNOLOGIA E CULTURA Ao final da década de 1980, iniciam-se as discussões para a elaboração da LDBEN, atendendo ao dispositivo constitucional que delega à União a competência privativa de legislar sobre as diretrizes e bases da educação nacional. Um projeto inicial, o Projeto de Lei n. 1.258/88, elaborado pelo deputado Octávio Elísio, do Partido da Social Democracia Brasileira (PSDB) de Minas Gerais, é enviado à Comissão de Educação da Câmara em novembro de 1988, com 83 artigos para regulamentação dos artigos que tratam da educação.

Para Oliveira (1997), o projeto original do deputado federal Octávio Elísio é baseado em um estudo elaborado por Dermeval Saviani, professor titular do Departamento de Filosofia e História de Educação da Faculdade de Educação da Universidade de Campinas (Unicamp), e nas sugestões preparadas por Jacques Velloso, professor titular da Faculdade de Educação da Universidade de Brasília (UnB), e Luiz Antônio Cunha, professor titular de Sociologia de Educação da Faculdade de Educação da Universidade Federal Fluminense (UFF). Dentre as teses que embasam esse projeto, destaca-se:

\section{[...] a tese da politecnia, que busca dar uma outra dire- ção ao ensino de 2. grau. A proposta da politecnia, como uma forma de se organizar o 2. grau, permitia que a dis- cussão em relação ao lugar e papel do ensino de 2. grau no conjunto do sistema nacional de educação pudesse ser mais precisamente colocada e abordada pelos educadores. (SAVIANI, 1990, p. $9^{2}$ apud OLIVEIRA, 1997, p. 33-34)}

Tese da politecnia baseada em um projeto educativo que tem o trabalho como princípio educativo, que possibilite não só a técnica, mas também a compreensão científica do objeto de estudo, uma educação que considere que todos os seres humanos, independentemente de sua classe social, têm o direito a uma educação que integre o pensar e o fazer, a teoria e a prática, conforme defesa de Gramsci (2001, p. 43):

O conceito e o fato do trabalho (da atividade teórico-prática) é o princípio educativo imanente à escola primária, já que a ordem social e estatal (direitos e deveres) é introduzida 
e identificada na ordem natural pelo trabalho. $\bigcirc$ conceito do equilíbrio entre ordem social e ordem natural com base no trabalho, na atividade teórico-prática do homem, cria os primeiros elementos de uma intuição do mundo liberta de toda magia ou bruxaria, e fornece o ponto de partida para o posterior desenvolvimento de uma concepção histórica, dialética, do mundo, para a compreensão do movimento e do devir, para a avaliação da soma de esforços e de sacrifícios que o presente custou ao passado e que o futuro custa ao presente, para a concepção da atualidade como síntese do passado, de todas as gerações passadas, que se projeta no futuro. É este o fundamento da escola primária.

Pretende-se, com essa tese, romper com a lógica fragmentada de uma educação profissional que se propõe apenas a treinar o estudante para a realização de uma tarefa específica para o mercado de empregos. A proposta apresentada pelo deputado Octávio Elísio é embasada em princípios que rompem com a formação profissional desvinculada da educação básica. Técnica, sim. Somente ela, não. Fazer e pensar juntos.

Oliveira (1997) pontua que um intenso debate nacional, coordenado pela Comissão de Educação da Câmara, inicia-se na elaboração da LDBEN. Nesse cenário, destaca-se a presença do Fórum Nacional em Defesa da Escola Pública (FNDEP) representando a sociedade civil organizada nas discussões da LDBEN. Os princípios defendidos pelo FNDEP são proclamados em um manifesto que possui seis grandes preceitos:

a. Escola pública como instância privilegiada na formação comprometida com uma transformação social;

b. Gestão democrática na escola e no sistema;

c. Escola Unitária, como organização didático-pedagógica tendo o trabalho como princípio educativo;

d. Investimento dos recursos públicos na educação pública;

e. Padrão universal de qualidade da escola pública;

f. Valorização dos profissionais da educação: excelência na formação dos educadores e piso salarial nacionalmente unificado. (FÓRUM NACIONAL EM DEFESA DA ESCOLA PÚBLICA NA LDB, $1989^{3}$ apud OLIVEIRA, 1997, p. 67)

3 FÓRUM NACIONAL EM DEFESA DA ESCOLA PÚBLICA NA LDB. Carta de princípios. Brasília, 9 ago. 1989. Mimeo. 
Nesse manifesto, a sociedade civil organizada, representada pelo FNDEP, reivindica, aos legisladores da Lei de Diretrizes e Bases, contemplar a Escola Unitária como organização didático-pedagógica que tem o trabalho como princípio educativo. A Escola Unitária representa, nesse contexto, a consolidação de um projeto de sociedade que tinha como centralidade o trabalho. Trabalho entendido na perspectiva marxista, como destacado por Engels (1974, p. 171), "condição fundamental primeira de toda a vida humana.”

Na contramão da lógica das relações sociais capitalistas em que os homens e mulheres são divididos entre os que pensam (os intelectuais) e os que fazem (os operacionais), ter o trabalho como princípio educativo é considerar que todos os seres humanos têm o direito a uma educação que integre o pensar e o fazer.

Para Gramsci (1982, p. 125), "o advento da Escola Unitária significa o início de novas relações entre trabalho intelectual e trabalho industrial não apenas na escola, mas em toda a vida social". Novas relações sociais contrárias à lógica hegemônica de divisão social do trabalho no capitalismo. Gramsci identifica que o desenvolvimento da Escola Unitária seria uma oportunidade de criar condições iguais para todas as camadas sociais, sem o fortalecimento da desigualdade de classe, já existente, como destaca:

Numa série de famílias, particularmente das camadas intelectuais, os jovens encontram na vida familiar uma preparação, um prolongamento e uma integração da vida escolar, absorvendo no "ar", como se diz, uma grande quantidade de noções e de aptidões que facilitam a carreira escolar propriamente dita: eles já conhecem e desenvolvem o conhecimento da língua literária, isto é, do meio de expressão e de conhecimento, tecnicamente superior aos meios possuídos pela média da população escolar dos seis aos doze anos. (GRAMSCI, 1982, p. 122)

Esse princípio integrador também é assumido por Vigotski (1994) ao abordar o rompimento com as relações de classe do modo de produção capitalista, pautadas na sobreposição do capital sobre o trabalho. Ao discutir como se 
dará a libertação do homem das amarras impostas por essa lógica excludente, Vigotski (1994), dentre outras raízes que desencadeiam a mudança do homem, acentua a importância da combinação do trabalho intelectual e manual:

[...] a mudança do homem reside no fato de que, ao mesmo tempo que velhas amarras desaparecem, um enorme potencial positivo presente em larga escala industrial, a sempre crescente força de desenvolvimento do ser humano sobre a natureza será libertada e tornar-se-á operativa. De todas as características discutidas acima, o exemplo mais brilhante de ser, a nova forma de criar um futuro inteiramente baseado na combinação trabalho intelectual e trabalho manual, o qual perderá sua característica dual, e mudará, de modo essencial, o rumo de sua influência. Ao passo que inicialmente suas ações eram dirigidas contra o povo, agora começam a trabalhar pela causa e interesse do povo. Desde seus papéis anteriores de obstáculos, eles agora se transformaram/converteram em poderosas forças impulsionadoras (VIGOTSKI, 1994, p. 181, grifos nossos)

Trabalho intelectual-manual. Rompimento com a característica dual e de instrumentalização culturalmente presente em nós e em toda a sociedade que naturaliza a negação de direitos, e de direitos qualitativos, para a classe trabalhadora. Iniciamos, assim, a década de 1990, com a semeadura de uma proposta de educação profissional para a LDB tendo como referência os princípios da politecnia. Essa perspectiva irá confrontar-se com a retomada da perspectiva da dualidade na formação básica e profissional, a partir desse período, como vemos no tópico que se segue.

\section{A PROPOSTA DE FORMAÇÃO PROFISSIONAL PARA ATENDIMENTO ESTRITO AO MERCADO DE EMPREGO}

A promulgação da Lei n. 9.394, de 20 de dezembro de 1996 (LDBEN), revela que a tese da politecnia defendida pelo projeto inicial do deputado Octávio Elísio não passa pelas legislaturas subsequentes e que permanece uma lógica de dualidade entre a formação básica e a formação profissional. 
Coerente com essa dualidade, inicia-se a implantação da reforma da educação profissional por meio do Decreto n. 2.208, de 17 de abril de 1997. Nesse período, já temos, como presidente do Brasil, Fernando Henrique Cardoso.

Segundo Manfredi (2002, p. 114), a instituição desse projeto é fruto de um processo histórico de disputas político-ideológicas empreendidas no âmbito da sociedade brasileira. A autora destaca que, naquele momento, existiam quatro grandes projetos em discussão, sendo dois no âmbito do Estado - o do Ministério do Trabalho e o do Ministério da Educação -, e dois no âmbito da sociedade civil organizada o de educadores e de organizações populares e sindicais e o de empresários industriais.

No âmbito do Estado, o projeto do Ministério do Trabalho, coordenado pela Secretaria de Formação e Desenvolvimento Profissional, desenvolve o Plano Nacional de Educação Profissional, o qual, na avaliação de Manfredi (2002, p. 115), "há em tal projeto a negação da dicotomia entre a Educação Básica e Educação Profissional e da sobreposição ou substituição da segunda pela primeira”. Por outro lado, o projeto do Ministério da Educação, elaborado pela Secretaria Nacional do Ensino Técnico (Senete), pelo relato de Manfredi (2002, p. 118), "não fortalece a integração da Educação Básica e da Educação Profissional”.

No âmbito da sociedade civil, o projeto de educadores e de organizações populares tem como base a articulação do FNDEP, presente na Assembleia Constituinte de 1988 e na elaboração da nova LDBEN. Segundo Manfredi (2002, p. 119), a proposta desse grupo defende a criação

[...] da escola básica unitária sustentada pela justificativa de construção de um sistema de educação nacional integrado que propicie a unificação entre trabalho, ciência, tecnologia e cultura.

O projeto apresentado pelos empresários industriais aproxima-se da proposta do Ministério da Educação ao defender

[...] aumento da escolaridade básica, da melhoria qualitativa da escola pública de nível fundamental e da reformulação e ampliação do atual sistema de ensino profissional, não questionando sua natureza dual. (MANFREDI, 2002, p. 128) 
A natureza dual refere-se à separação da educação profissional da educação básica.

Em meio às disputas estabelecidas entre esses quatro projetos, com consensos e dissensos, é instituída a reforma da educação profissional por meio do Decreto n. 2.208/97. Com esse ato normativo, estabelecem-se os níveis adquiridos por essa modalidade de ensino:

Art. 3. A Educação Profissional compreende os seguintes níveis:

I - básico: destinado à qualificação, requalificação e reprofissionalização de trabalhadores, independente de escolaridade prévia;

II - técnico: destinado a proporcionar habilitação profissional a alunos matriculados ou egressos do ensino médio, devendo ser ministrado na forma estabelecida por este Decreto;

III - tecnológico: correspondente a cursos de nível superior na área tecnológica, destinados aos egressos do ensino médio e técnico. (BRASIL, 1997)

Kuenzer e Ferretti (1999 apud MANFREDI, 2002, p. 134) afirmam que essa reforma repõe a dualidade estrutural,

1 - não reconhecendo a educação básica como fundamental para a formação científico-tecnológica sólida dos trabalhadores, demandada pela nova etapa de desenvolvimento das forças produtivas, contrariando uma tendência que é mundialmente aceita e defendida por empresários, trabalhadores e governos; 2- Supõe ruptura entre o acadêmico, desvalorizado por não ser prático, e o tecnológico, não reconhecendo o caráter transdisciplinar da ciência contemporânea, reforçando a ideia de duas redes, para acadêmicos e para trabaIhadores, ao melhor estilo taylorista, que separa dirigentes de especialistas, concepção que hoje é questionada até pela organização capitalista de produção.

Kuenzer e Ferretti (1999) compreendem que a organização da educação profissional estabelecida pelo Decreto n. 2.208/97, básica, técnica e tecnológica, "repõe a dualidade estrutural" do capitalismo, que separa os detentores do capital dos detentores da força de trabalho. Em outras palavras, separa o pensar e a
4 KUENZER, Acácia Zeneida; FERRETI, Celso. Políticas públicas referentes à formação profissional no Brasil. 1999. Mimeo. 
ciência do fazer e da técnica. Nesse raciocínio, a formação dos trabalhadores é realizada a partir da perspectiva do treinamento para execução de tarefas específicas e pontuais.

Apesar dos posicionamentos contrários à reforma, principalmente no que se refere à importância da educação básica para a formação científico-tecnológica, em 1999, aprofundando os fundamentos desse decreto, são publicadas as Diretrizes Curriculares Nacionais (DCNs) para a Educação Profissional de Nível Técnico, por meio da Resolução CNE/CBE n. 4, de 8 de dezembro de 1999.

A década de 1990 fica marcada pela hegemonia neoliberal em todos os níveis e modalidades de ensino, principalmente na educação profissional, em que se legitima, com o Decreto n. 2.208/97, a separação da educação profissional da educação básica. Vale salientar o contexto socioeconômico do Brasil na década de 1990. A lógica neoliberal começa a dominar os programas e projetos públicos brasileiros. Segundo Oliveira (1997, p. 143),

[...] o neoliberalismo nasce logo após a II Guerra Mundial, na Europa e na América do Norte, onde imperava o capitalismo e constitui-se numa reação teórica e política forte contra o Estado intervencionista e de Bem Estar.

Dentre os princípios básicos dessa corrente ideológica, destacam-se: o da liberdade e da primazia do mercado sobre o Estado; o do individual sobre o coletivo; e, derivadamente, o do Estado Mínimo, ou seja, aquele que não intervém no livre jogo dos agentes econômicos.

\section{A PRIMEIRA DÉCADA DO SÉCULO XXI - RUPTURA OU CONTINUIDADE DA DISPUTA?}

Ao final de 2002, temos mais uma eleição presidencial e, em janeiro de 2003, assume a Presidência da República Luís Inácio Lula da Silva, permanecendo até dezembro de 2010. Em relação à educação profissional, no segundo ano desse governo, em 2004, após um intenso debate com os estados e a sociedade civil organizada, é instituído o primeiro marco normativo da educação profissional, que reabre a possibilidade de implantação dessa modalidade integrada à educação básica, o Decreto n. 5.154, de 23 de julho de 2004, 
que regulamenta o $\S 2 .^{\circ}$ do art. 36 e os artigos 39 a 41 da Lei n. 9.394/96 e revoga o então vigente Decreto n. 2.208/97.

Com esse novo decreto, no art. $4^{\circ}$, abre-se uma nova possibilidade de oferta de educação profissional integrada à educação básica, item não contemplado pelo Decreto n. 2.208/97:

Art. $4^{\circ}[\ldots] \S 1^{\circ}$ articulação entre a Educação Profissional técnica de nível médio e o ensino médio dar-se-á de forma:

I - integrada, oferecida somente a quem já tenha concluído o ensino fundamental, sendo o curso planejado de modo a conduzir o aluno à habilitação profissional técnica de nível médio, na mesma instituição de ensino, contando com matrícula única para cada aluno;

II - concomitante, oferecida somente a quem já tenha concluído o ensino fundamental ou esteja cursando o ensino médio, na qual a complementaridade entre a Educação Profissional técnica de nível médio e o ensino médio pressupõe a existência de matrículas distintas para cada curso [...]

III - subseqüente, oferecida somente a quem já tenha concluído o ensino médio. (BRASIL, 2004)

Não se eliminam as demais formas instituídas pelo decreto anterior, a subsequente e a concomitante; porém, abre-se a possibilidade para a integração, que, até então, não está contemplada e é a almejada para os que ainda estão no ensino fundamental. Assim, no art. $4^{\circ}$, existem três possibilidades de oferta: integrada, concomitante e subsequente. A forma integrada reabre a possibilidade da formação integral: "Em termos ainda somente formais, o Decreto n. 5.154/2004 tenta restabelecer as condições jurídicas, políticas e institucionais que se queria assegurar na disputa da LDB na década de 1980" (FRIGOTTO; CIAVATTA; RAMOS, 2005, p. 11). Essas disputas dizem respeito à tese da politecnia, tese baseada em um projeto educativo que tem o trabalho como princípio educativo, que almeja uma formação para o trabalhador que integre trabalho, ciência, tecnologia e cultura.

Na contramão desse processo, nas disposições do Decreto n. 5.154/2004, há uma atualização, por meio da Resolução 
Nacional de Educação do Conselho Nacional de Educação/ Câmara de Educação Básica (CNE/CEB) n. 1, de 3 de fevereiro de 2005, das Diretrizes Curriculares Nacionais definidas pelo Conselho Nacional de Educação para o ensino médio e para a educação profissional técnica de nível médio. Essa resolução, porém, não altera a lógica central de construção dos cursos - formação profissional, de um lado, e formação geral do outro -, permanecendo como orientação para a construção dos cursos de educação profissional as diretrizes encerradas na Resolução CNE/CBE n. 4, de 8 de dezembro de 1999, que regulamenta o Decreto n. 2.208/97.

Apesar de o Decreto n. 5.154/2004 contemplar a perspectiva integrada de educação, as diretrizes para sua operacionalização ainda estão vinculadas aos princípios do decreto anterior. Isso está explícito na nova resolução: "Art. 8..$^{\circ}$ ficam mantidas as Resoluções CNE/CEB n. 03/98 e 04/99, com alterações introduzidas por esta resolução" (BRASIL, 2005). Assim, institui-se o Decreto n. 5.154/2004, revogando o Decreto n. 2.208/97, porém as diretrizes curriculares nacionais definidas pelo CNE para o ensino médio e para a educação profissional técnica de nível médio não alteram a lógica de fragmentação vigente e implantada com o Decreto n. 2.208/97, que separa a educação profissional da educação básica.

Em 2008, a Lei de Diretrizes e Bases da Educação Nacional, Lei n. 9.394/1996, é alterada pela Lei n. 11.741, de 16 de julho de 2008, incorporando as questões fundamentais trazidas pelo Decreto n. 5.154/2004:

Art. 36-B. A educação profissional técnica de nível médio será desenvolvida nas seguintes formas (Incluído pela Lei

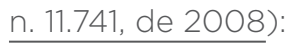

I - articulada com o ensino médio (Incluído pela Lei n. 11.741, de 2008);

II - subseqüente, em cursos destinados a quem já tenha concluído o ensino médio (Incluído pela Lei n. 11.741, de 2008) [...].

Art. 36-C. A educação profissional técnica de nível médio articulada, prevista no inciso I do caput do art. 36-B desta Lei, será desenvolvida de forma (Incluído pela Lei n. 11.741, de 2008): 
I - integrada, oferecida somente a quem já tenha concluído o ensino fundamental, sendo o curso planejado de modo a conduzir o aluno à habilitação profissional técnica de nível médio, na mesma instituição de ensino, efetuando-se matrícula única para cada aluno (Incluído pela Lei n. 11.741, de 2008);

II - concomitante, oferecida a quem ingresse no ensino médio ou já o esteja cursando, efetuando-se matrículas distintas para cada curso, e podendo ocorrer (Incluído pela Lei n. 11.741, de 2008) [...]. (BRASIL, 1996, grifos nossos)

Como destacado no inciso primeiro do art. 36-C, a forma integrada, até então presente somente no Decreto n. 5.154/2004, é assumida pela Lei de Diretrizes e Bases da Educação Nacional. Assim, do ponto de vista legal, na primeira década do século XXI, percebe-se que é estabelecido um arcabouço legal para a viabilização da política de integração da educação profissional com a educação básica, inclusive na modalidade de educação de jovens e adultos, com programas como o Programa Nacional de Integração da Educação Profissional com a Educação Básica na Modalidade de Educação de Jovens e Adultos (Proeja).

Não obstante o avanço legal, Bastos e Vitorette (2011, p. 334) pontuam que houve, em termos de política econômica, a continuidade da política do governo Fernando Henrique Cardoso, "não se rompendo, assim, com as diretrizes desenvolvidas pelo governo anterior, o que significou uma autorreforma do capitalismo no Brasil."

Vale ressaltar ainda que, na primeira metade do século XXI, inicia-se a elaboração das novas Diretrizes Curriculares Nacionais para a Educação Profissional Técnica de Nível Médio. Até esse momento, estavam em vigor as Diretrizes Curriculares para a Educação Profissional Técnica de Nível Médio aprovadas em 1999, sob a égide da proposta neoliberal de educação.

Conforme descrição de Bastos e Vitorette (2011), na elaboração das novas diretrizes, prevalecia a disputa entre dois projetos, um que reforçava a proposta da década de 1990, denominado “Atualização das Diretrizes Curriculares Nacionais para a Educação Profissional Técnica de Nível Médio e 
Projeto de Resolução" (BRASIL, 2010a), e outro que tentava resgatar a proposta da politecnia da década de 1980 , politecnia baseada em um projeto educativo que tem o trabalho como princípio educativo, que possibilite não só a técnica, mas também a compreensão científica do objeto de estudo, com o nome Diretrizes Curriculares Nacionais para o Ensino Médio em Debate (BRASIL, 2010b).

Naquele momento, a Secretaria de Educação Profissional e Tecnológica do Ministério da Educação, formada por dirigentes que tinham clareza da aprovação de uma diretriz baseada nos princípios da politecnia, apoia essa proposta e produz, conjuntamente com demais atores da educação profissional e da educação básica, o documento Diretrizes Curriculares Nacionais para o Ensino Médio em Debate:

No documento Diretrizes Curriculares Nacionais para o Ensino Médio em Debate, conforme os estudos de Frigotto, a formação profissional integrada assume outra dimensão, ou seja, pressupõe assumir a formação integrada como princípio educacional, como possibilidade para superar a dimensão pragmática que direciona a educação à utilidade, funcionalidade. (BASTOS; VITORETTE, 2011, p. 340)

Desse processo, é aprovada, com base no Parecer CNE/CEB n. 11, de 9 de maio de 2012, a Resolução CNE/CEB n. 6, de 20 de setembro de 2012, que define as Diretrizes Curriculares Nacionais para a Educação Profissional Técnica de Nível Médio. Essa Resolução, constituída no espaço de disputa desses dois projetos, contém, na nossa avaliação, avanços no que se refere à concepção da educação profissional proposta, como, por exemplo, o "Art. 6 [...] III - trabalho assumido como princípio educativo, tendo sua integração com a ciência, a tecnologia e a cultura como base da proposta político-pedagógica e do desenvolvimento curricular" (BRASIL, 2012).

Entretanto, essas diretrizes não conseguem deter a força do capital, já que, no mesmo período de sua aprovação, é promulgada a Lei do Pronatec, que, como veremos a seguir, aprofunda a concepção de formação profissional para atendimento das demandas do mercado de emprego. Essa é a contradição que destacamos com a emergência desse 
programa. Se, por um lado, temos uma diretriz que amplia os objetivos da educação profissional para além da preparação para o mercado de empregos, por outro, temos a execução de um programa bilionário que, hegemonicamente, parece trabalhar na perspectiva de conformidade à lógica do capital.

IMPLEMENTAÇÃO DO PROGRAMA NACIONAL DE ACESSO AO ENSINO TÉCNICO E EMPREGO (PRONATEC): HEGEMONIA DA PROPOSTA NEOLIBERAL?

Em $1^{\circ}$ janeiro de 2011, assume a Presidência da República Dilma Rousseff, como nome indicado e apoiado pelo presidente anterior, Luiz Inácio Lula da Silva, representando a coligação dos seguintes partidos: Partido dos Trabalhadores (PT), Partido do Movimento Democrático Brasileiro (PMDB), Partido Democrático Trabalhista (PDT), Partido Comunista do Brasil (PC do B), Partido Progressista (PP), Partido da República (PR), Partido Social Democrático (PSD), Partido Republicano da Ordem Social (PROS) e Partido Republicano Brasileiro (PRB). No que se refere à política de educação profissional, o grande marco normativo da então presidenta foi a Lei n. 12.513, de 26 de outubro de 2011, que instituiu, em âmbito nacional, o Programa Nacional de Acesso ao Ensino Técnico e Emprego (Pronatec) para atender, segundo divulgação do governo, oito milhões de trabalhadores até 2014:

Por meio da atuação conjunta destes parceiros, o Pronatec conseguiu cumprir a meta de oferta de 8 milhões de matrículas entre 2011 e 2014, alcançando mais de 4.000 municípios, com oferta de mais de 200 cursos técnicos, e mais de 600 cursos com carga horária mínima de 160 horas, destinados à formação inicial e continuada (FIC), ambos definidos pelo Ministério da Educação. (FERES, 2014, p. 130)

Importante salientar que a lei inicial de criação desse programa não contempla, em seus dispositivos, a integração da educação profissional com a educação básica, proposta política que havia sido retomada, em 2004, com a instituição do Decreto n. 5.154/2004, em 2005/2006, com a criação 
do Proeja, Decreto n. 5.840/2006, em 2008, com a alteração da LDB pela Lei n. 11.741 de 2008 e, por fim, em 2012, com a instituição das Diretrizes Curriculares Nacionais para a Educação Profissional Técnica de Nível Médio. Vale salientar que, pelo menos do ponto de vista formal, a proposta de integração da educação básica com a educação profissional dispõe-se a uma oferta de formação mais integral, conforme princípios já apresentados ao longo do artigo.

Essa omissão da terminologia "integrada" no texto inicial do programa nos faz refletir sobre o objetivo final da política que está sendo instituída. Identificamos que há um distanciamento entre as concepções da educação profissional vigentes no Pronatec e nas que fomentam cursos integrados. Esse distanciamento é diminuído em 2013, com a alteração do Pronatec, através da Lei n. 12.816, de 5 de junho de 2013. Por meio dessa lei, reabre-se a possibilidade de financiamento de cursos integrados pelo Pronatec, inclusive na modalidade de educação de jovens e adultos.

Embora em 2013 o Pronatec passe a contemplar a integração, em termos de discurso oficial, permanece a lógica de formação do trabalhador como mão de obra que é formada para aumentar a produtividade e a competitividade do país, conforme discurso de um dos dirigentes do Ministério da Educação:

Dentre os desafios do Pronatec podem ser destacados: a indução da oferta dos cursos em função da demanda por formação profissional, o atendimento dos diversos perfis de públicos prioritários do Programa e o processo de intermediação de mão de obra para os egressos do Pronatec. Portanto, o Pronatec se configura como política pública de educação profissional de extrema relevância. Por um lado, ele possibilita a inclusão social, por meio do atendimento aos diversos públicos que necessitam da formação profissional, e por outro, ele contribui para a meIhoria da produtividade e da competitividade do país, por meio das ofertas de cursos profissionalizantes que atendem aos mais diversos setores. (FERES, 2014, p. 130, grifos nossos) 
Assim como nos programas analisados por Rummert e Alves (2010), percebemos, no discurso oficial dos dirigentes do governo, que no Pronatec há uma relação que se quer estabelecer entre a oferta e a demanda do mercado de emprego. A formação profissional dos trabalhadores é vista como salvacionista para o desenvolvimento econômico do país, esquivando-se de uma discussão real sobre os fundamentos da crise estrutural do capitalismo. Entretanto, o argumento que automatiza a relação formação profissional e crescimento do país parece não se sustentar. Basta analisarmos os quatro anos de investimento no Pronatec, com formação de oito milhões de pessoas, segundo dados do governo, e um crescimento econômico em 2014 de $0,1 \%$, conforme dados do Instituto Brasileiro de Geografia e Estatística (IBGE). ${ }^{5}$

O Pronatec tem como ação central o financiamento da "Bolsa Formação". Com sua implementação, em 2011, houve uma articulação política para que as demais ações, já em curso no governo anterior, fizessem parte do programa e rendessem números quantitativos de matrícula para as campanhas publicitárias do atual governo. Entretanto, o que chega efetivamente como carro-chefe do programa é a denominada "Bolsa Formação".

Sobre esse assunto, encontramos uma análise no blog do Movimento de Valorização e Articulação dos Trabalhadores em Educação do Ministério da Educação (Movate) MEC. ${ }^{6}$ Segundo esse movimento, os cursos de qualificação profissional ofertados pelo Pronatec-Bolsa Formação são rápidos, de baixa complexidade tecnológica e desvinculados da elevação de escolaridade. Com isso, perpetua-se,

[...] a lógica de manutenção de um sistema em que os trabalhadores e trabalhadoras continuam recebendo uma formação rasa, para execução de tarefas rudimentares, ao melhor estilo 'fordista'?

Reforçando essa análise do Movate, a Confederação Nacional dos Trabalhadores em Educação (CNTE) também se pronunciou em relação ao projeto do Pronatec:

Tal como se apresenta o projeto do Pronatec, os eixos dos cursos passam, prioritariamente, pela qualificação pro-
5 O Movimento de Valorização e Articulação dos Trabalhadores em Educação do MEC (Movate), instituído formalmente em 27 de novembro de 2007, é uma entidade civil, sem fins lucrativos, independente de qualquer atividade político-partidária, com atuação precípua no âmbito do Ministério da Educação e em todo território nacional, com sede no Distrito Federal.

6 O Movimento de Valorização e Articulação dos Trabalhadores em Educação do MEC (Movate), instituído formalmente em 27 de novembro de 2007, é uma entidade civil, sem fins lucrativos, independente de qualquer atividade político-partidária, com atuação precípua no âmbito do Ministério da Educação e em todo território nacional, com sede no Distrito Federal

7 Análise disponivel em: <http://www. movate.org/2014/04/pronatec-o-quefica-com-os-fic.html>. Acesso em: 28 set. 2015 
fissional de curta duração e pela formação técnica-profissional concomitante ao ensino médio, desprezando, portanto, as premissas curriculares e o papel social da formação dos(as) trabalhadores(as), construídos nos últimos sete anos. O reducionismo curricular atende aos interesses dos agentes produtivos (interessados apenas na qualificação operacional da mão de obra), os quais, para que seus objetivos sejam atingidos com segurança, optaram por direcionar a formação a cursos e instituições privadas, com currículos adstritos aos interesses corporativos. (CONFEDERAÇÃO NACIONAL DOS TRABALHADORES EM EDUCAÇÃO - CNTE, 2011, p. 182-183)

Nessa nota da CNTE, há mais uma análise que questiona os fundamentos curriculares do Pronatec que estão na contramão do que se vinha construindo nos últimos anos "desprezando, portanto, as premissas curriculares e o papel social da formação dos(as) trabalhadores(as), construídos nos últimos sete anos" (CNTE, 2011, p. 182). Aqui, a CNTE relembra os marcos legais que defendiam a proposta da integração da educação profissional com a educação básica, o Decreto n. 5154/2004, o Decreto n. 5840/2006 e a Resolução CNE/CEB n. 06, de 20 de setembro de 2012, que define as Diretrizes Curriculares Nacionais para a Educação Profissional Técnica de Nível Médio.

Ainda em relação à organização do programa, mais especificamente a ação do Pronatec-Bolsa Formação, é importante compreender que se trata de um recurso financeiro, no valor de R \$10,00 hora/aula/aluno, destinado às instituições que ofertam cursos de qualificação profissional ou técnico. Assim, para um curso de qualificação profissional em agente administrativo de 160 horas para 40 alunos, é destinado o montante de $\mathrm{R} \$ 64.000,00$ (sessenta e quatro mil reais). Vale ressaltar que os cursos mais ofertados pela ação Bolsa Formação são os de baixa complexidade tecnológica, como o de agente administrativo.

Embora os dados encontrados sobre os quantitativos de matrículas do Pronatec e especificamente da ação Bolsa Formação sejam precários, há um indicativo de que o maior quantitativo da oferta e matrícula está concentrado nos 
cursos de qualificação profissional, de no mínimo 160 horas, e não possuem vinculação com a educação básica.

As principais instituições que ofertam os cursos da ação Bolsa Formação são as do Sistema S (Serviço Social da Indústria - Sesi; Serviço Nacional de Aprendizagem na Indústria - Senai; Serviço Nacional de Aprendizagem Comercial - Senac; Serviço Nacional de Aprendizagem Rural - Senar; Serviço Nacional de Aprendizagem em Transportes - Senat), a rede federal e os sistemas estaduais. As faculdades privadas também fazem parte do escopo de entidades consideradas ofertantes do programa, podendo oferecer cursos técnicos subsequentes.

Outro ponto importante a destacar é que os cursos da ação Bolsa Formação são lecionados por profissionais contratados como bolsistas, destituídos de qualquer vínculo empregatício ou mesmo formação docente, conforme Lei n. 12.513, de 26 de outubro de 2011 que institui o programa:

\section{Art. $8^{\circ}[\ldots] \& 3^{\circ}$ As atividades exercidas pelos profissio- nais no âmbito do Pronatec não caracterizam vínculo em- pregatício e os valores recebidos a título de bolsa não se incorporam, para qualquer efeito, ao vencimento, salário, remuneração ou proventos recebidos. (BRASIL, 2011)}

Essa situação aprofunda uma cultura de precarização dos profissionais que trabalham em cursos da área de educação profissional e tecnológica.

O Pronatec insere-se no cenário nacional como sendo o programa linha de frente do governo. Com a lógica de oferta-demanda, ele se institui como programa, com foco no atendimento das demandas do mercado de emprego e no aumento da competitividade do país. Conforme argumentação de Rummert e Alves (2010), essa lógica salvacionista dos programas para formação profissional não realiza o aprofundamento necessário dos problemas estruturantes gerados pelo modo de produção capitalista. A Bolsa Formação do Pronatec torna-se, assim, mais um simulacro de educação que precariamente atende o trabalhador e, bilionariamente, o capital, consubstanciado aqui, nas grandes corporações de formação profissional e agora também de educação superior, já que as faculdades privadas passam a acessar os recursos desse programa. 


\section{CONSIDERAÇÕES FINAIS}

As análises realizadas neste artigo não têm caráter conclusivo, pois acreditamos que um programa da envergadura do Pronatec precisa ser continuamente investigado, já que é recente e o estudo do seu impacto deve ser analisado em médio e longo prazos. Nesse artigo, trazemos algumas contribuições ao debate, ao apresentarmos as concepções vigentes que permeiam a formação profissional dos trabalhadores. São análises iniciais que já nos revelam algo, mas ainda precisam de mais aprofundamentos.

Pela trajetória realizada, ficam evidentes duas grandes concepções que estão em permanente disputa: uma vinculada ao atendimento do capital, que enxerga a formação do trabalhador como formação de mão de obra para aumento da competividade e produtividade econômica do país; e outra que busca a formação de um ser humano integral, baseada em um projeto de emancipação humana, que inclusive questiona a lógica de estruturação dual do modo de produção capitalista.

A primeira concepção tende a fortalecer a dualidade estrutural do capitalismo, que divide os homens e mulheres entre os que realizam o trabalho mecânico e os que realizam o trabalham intelectual. O pensar e o fazer dissociados, fortalecendo a divisão de classe e as desigualdades sociais. A segunda concepção já aponta para a possibilidade de uma reintegração do ser humano dividido. Nessa perspectiva, os homens e mulheres não estariam divididos entre os que pensam e os que fazem. Todos são convidados a pensar e fazer.

Com essa segunda concepção, admite-se a possibilidade de criar rupturas, uma instabilizacão na estruturação hegemônica que vem se constituindo nos cursos de formação de trabalhadores. Concordamos com Vigotski (1994) que a mudança do homem tem como seu principal fundamento a combinação do trabalho intelectual e trabalho manual:

[...] o exemplo mais brilhante de ser, a nova forma de criar um futuro inteiramente baseado na combinação trabalho intelectual e trabalho manual, o qual perderá sua característica dual, e mudará, de modo essencial, o rumo de sua influência. (VIGOTSKI, 1994, p. 181) 


\section{Nossas buscas e escolhas epistemológicas indicam que o Pronatec se distancia dos marcos normativos da integração que se constituem a partir de 2004 , com a promulgação do Decreto n. 5.154/2004, e se alinha hegemonicamente às con- cepções que tendem a fortalecer a formação do trabalhador em conformidade com a lógica do capital.}

\section{REFERÊNCIAS}

BASTOS, Rachel B. M.; VITORETTE, Jacqueline M. B. Trabalho e educação profissional: concepções em disputa. In: MACHADO, Maria Margarida; RODRIGUES, Maria Emília. (Org.). Educação dos trabalhadores: políticas e projetos em disputas. Campinas, SP: Mercado de Letras, 2011.

BRASIL. Projeto de Lei n. 1.258/1988, que fixa as Diretrizes e Bases da Educação Nacional. Brasília, DF, 28 nov. 1988. Texto original. Disponível em: <http://www.camara.gov.br/proposicoesWeb/prop_ mostrarintegra;jsessionid=598B103AFF8CEC004E2394D085CCDA1B.proposi coesWeb2 codteor=1154749\&filename=Dossie+-PL+1258/1988> . Acesso em: 17 set. 2016.

BRASIL. Lei n. 9.394, de 20 de dezembro de 1996. Estabelece as diretrizes e bases da educação nacional. Diário Oficial [da] República Federativa do Brasil, Brasília, DF, 23 dez. 1996. Disponível em: <http://www.planalto.gov.br/ ccivil_03/Leis/L9394.htm>. Acesso em: 28 dez. 2010.

BRASIL. Decreto n. 2.208, de 17 de abril de 1997. Regulamenta o $§ 2 .^{\circ}$ do art. 36 e os arts. 39 a 42 da Lei n. 9.394, de 20 de dezembro de 1996, que estabelece as diretrizes e bases da educação nacional. Diário Oficial [da] República Federativa do Brasil, Brasília, DF, 18 abr. 1997. Disponível em: <http://www.planalto.gov.br/ccivil_03/decreto/D2208.htm>. Acesso em: 20 dez. 2010.

BRASIL. Decreto n. 5.154, de 23 de julho de 2004. Regulamenta o $§ 2 .^{\circ}$ do art. 36 e os artigos 39 a 41 da Lei n. 9.394, de 20 de dezembro de 1996, que estabelece as diretrizes e bases da educação nacional, e dá outras providências. Diário Oficial [da] República Federativa do Brasil, Brasília, DF, 28 jul. 2004. Disponível em: <http://www.planalto.gov.br/ccivil_03/_Ato20042006/2004/Decreto/D5154.htm>. Acesso em: 20 dez. 2010.

BRASIL. Decreto n. 5.840, de 13 de julho de 2006. Institui, no âmbito federal, o Programa Nacional de Integração da Educação Profissional à Educação Básica na Modalidade de Educação de Jovens e Adultos - Proeja. Diário Oficial [da] República Federativa do Brasil, Brasília, DF, 14 jun. 2006. Disponível em: <http://www.planalto.gov.br/ccivil_03/_Ato2004-2006/2006/Decreto/D5840. htm\#art11>. Acesso em: 20 dez. 2010.

BRASIL. Lei n. 11.741, de 16 de julho de 2008. Altera dispositivos da Lei n: 9.394, de 20 de dezembro de 1996, que estabelece as diretrizes e bases da educação nacional, para redimensionar, institucionalizar e integrar as ações da educação 
profissional técnica de nível médio, da educação de jovens e adultos e da educação profissional e tecnológica. Diário Oficial [da] República Federativa do Brasil, Brasília, DF, 17 jul. 2008. Disponível em: <http://www.planalto.gov.br/ccivil_03/_ Ato2007-2010/2008/Lei/L11741.htm>. Acesso em: 25 de jun. de 2015.

BRASIL. Atualização das Diretrizes Curriculares Nacionais para a Educação Profissional Técnica de Nivel Médio - versão preliminar para debates na audiência pública nacional. Brasília, DF: CNE/CEB, 2010a.

Disponível em: <http://portal.mec.gov.br/index.php?option=com content\&view=article\&id=13556\&Itemid=956> . Acesso em: 05 maio 2011.

BRASIL. Diretrizes curriculares nacionais para o ensino médio em debate. Brasília, DF: MEC/SEB/SETEC, 2010b. Disponível em: <http://portal.mec.gov.br/index. php?option=com_content\&view=article $\&$ id=12924:artigos\&catid=190:setec $>$. Acesso em: 25 jun. 2015.

BRASIL. Lei n. 12.513, de 26 de outubro de 2011. Institui o Programa Nacional de Acesso ao Ensino Técnico e Emprego (Pronatec); altera as Leis n. 7.998, de 11 de janeiro de 1990, que regula o Programa do Seguro-Desemprego, o Abono Salarial e institui o Fundo de Amparo ao Trabalhador (FAT), n. 8.212, de 24 de julho de 1991, que dispõe sobre a organização da Seguridade Social e institui Plano de Custeio, n. 10.260, de 12 de julho de 2001, que dispõe sobre o Fundo de Financiamento ao Estudante do Ensino Superior, e n. 11.129, de 30 de junho de 2005, que institui o Programa Nacional de Inclusão de Jovens (ProJovem); e dá outras providências. Diário Oficial [da] República Federativa do Brasil, Brasília, DF, 27 out. 2011. Disponível em: <http://www.planalto.gov.br/ ccivil_03/_ato2011-2014/2011/lei/112513.htm>. Acesso em: 14 set. 2016.

BRASIL. Ministério da Educação. Conselho Nacional de Educação. Resolução CNE/CEB n. 4, de 8 de dezembro de 1999. Institui as Diretrizes Curriculares Nacionais para a Educação Profissional de Nível Técnico. Brasília, DF, 1999. Disponível em: <http://portal.mec.gov.br/cne/arquivos/pdf/rceb04_99.pdf>. Acesso em: 25 jun. 2015.

BRASIL. Ministério da Educação. Conselho Nacional de Educação. Resolução CNE/CEB n. 1, de 3 de fevereiro de 2005. Atualiza as Diretrizes Curriculares Nacionais para a Educação de Jovens e Adultos. Brasília, DF, 2005. Disponível em: <http://portal.mec.gov.br/setec/arquivos/pdf1/proejaresolucao01_05. pdf>. Acesso em: 25 jun. 2015.

BRASIL. Ministério da Educação. Conselho Nacional de Educação. Resolução CNE/CEB n. 06, de 20 de setembro de 2012. Institui as Diretrizes Curriculares Nacionais para a Educação Profissional de Nível Técnico. Brasília, DF, 2012. Disponível em: <http://portal.mec.gov.br/index.php?option=com content\&id=17417\&Itemid=866> . Acesso em: 25 jun. 2015.

CASSIOLATO, Maria Martha M. C.; GARCIA, Ronaldo Coutinho. Pronatec: múltiplos arranjos e ações para ampliar o acesso à educação profissional. Rio de Janeiro: Ipea, 2014. (Texto para Discussão, 1919).

CONFEDERAÇÃO NACIONAL DOS TRABALHADORES EM EDUCAÇÃO CNTE. Os riscos do Pronatec para a educação técnica profissional. Revista Retratos da Escola, Brasília, DF, v. 5, n. 8, p. 179-184, jan./jun. 2011. Disponível em: <http://www.esforce.org.br>. Acesso: 10 out. 2015 
ENGELS, Friedrich. Dialética da natureza. Lisboa: Presença Ltda., 1974.

FERES, Marcelo Machado. O Programa Nacional de Acesso ao Ensino Técnico e Emprego (Pronatec): resultados e desafios. Boletim Técnico Senac, Rio de Janeiro, v. 40, n. 3, p. 128-135, set./dez. 2014.

FRIGOTTO, Gaudêncio; CIAVATTA, Maria; RAMOS, Marise. A gênese do Decreto n. 5154/2004: um debate no contexto controverso da democracia restrita. Trabalho necessário, Rio de Janeiro, v. 3, n. 3, p. 1-26, 2005.

GRAMSCI, Antonio. Os intelectuais e a organização da cultura. Rio de Janeiro: Civilização brasileira, 1982.

GRAMSCI, Antonio. Cadernos do cárcere. Edição e tradução de Carlos Nelson Coutinho; coedição de Luiz Sérgio Henriques e Marco Aurélio Nogueira. 2. ed. Rio de Janeiro: Civilização Brasileira, 2001.

MANFREDI, Maria Silvia. Educação profissional no Brasil. São Paulo: Cortez, 2002.

OLIVEIRA, Regina Tereza C. de. LDB e o contexto nacional: o papel dos partidos políticos na elaboração dos projetos de 1988 a 1996. 1997. Tese (Doutorado) Faculdade de Educação, Universidade de Campinas, Campinas, SP, 1997.

RUMMERT, Sonia Maria; ALVES, Natália. Jovens e adultos trabalhadores pouco escolarizados no Brasil e em Portugal: alvos da mesma lógica de conformidade, Revista Brasileira de Educação, v. 15 n. 45, set./dez. 2010.

VIGOTSKI, Lev S. O significado histórico da crise da psicologia: uma investigação metodológica. In: VYGOTSKI, Lev S. Teoria e método em psicologia. São Paulo: Martins Fontes, 1994.

\section{MARIA CLARISSE VIEIRA}

Professora da Faculdade de Educação da Universidade de Brasília (UnB); Brasília, Distrito Federal, Brasil mclarissev@yahoo.com.br

\section{RENATO HILÁRIO DOS REIS}

Professor da Faculdade de Educação da Universidade de Brasília (UnB); Brasília, Distrito Federal, Brasil

hilarioreis@uol.com.br

JULIETA BORGES LEMES SOBRAL

Doutoranda da Faculdade de Educação da Universidade de Brasília (UnB); Brasília, Distrito Federal, Brasil

jujucampanha@gmail.com

Recebido em: JUNHO 2016

Aprovado para publicação em: JULHO 2016 